\title{
Age-specific parental knowledge of restraint transitions influences appropriateness of child occupant restraint use
}

Lynne Bilston $^{1}$, Caroline Finch ${ }^{2}$, Julie Hatfield ${ }^{3}$, Julie Brown ${ }^{1}$

${ }^{1}$ Prince of Wales Medical Research Institute, University of NSW

${ }^{2}$ School of Human Movement \& Sport Sciences, University of Ballarat

${ }^{3}$ Injury Risk Management Research Centre, University of NSW 


\section{Abstract}

Objective. To determine the factors that influence appropriate restraint usage by child occupants across the age range for which any type of child restraint may be appropriate ( $0-10$ years).

Design. Randomised household telephone survey

Setting. Statewide survey, New South Wales, Australia

Subjects. Parents or carers of children aged 0-10 years

Main outcome measures. Parental reporting of appropriateness of child restraint

Methods. Demographic information and data on age, size, restraint practices, parental knowledge of child occupant safety and attitude to restraint use was collected using a structured interview. Data was analysed using logistic regression after cluster adjustment.

Results. Inappropriate restraint use by children was widespread, particularly in children aged 2+ years. Overall, parental knowledge of appropriate ages for restraint transitions was associated with increased likelihood of appropriate restraint use. Lower levels of formal parental education, larger families, parental restraint non-use and parent/child negotiability of restraint use were predictors of inappropriate restraint use. For particular child age sub-groups, the parental knowledge that predicted appropriate restraint use was specific to that age group. The majority of parents felt that they knew enough to safely restrain their child, despite widespread inappropriate restraint use.

Conclusions. Parents are more likely to make appropriate restraint choices for their children if they possess restraint knowledge specific to their children's age and size. Educational campaigns may be most effective when they provide information for specific ages and transition points. Strategies to overcome parents' misplaced confidence that they know enough to restrain their children safely are also indicated.

Keywords: "child restraint", "booster seat", "motor vehicle passenger", "restraint knowledge" Running Head: "Parental knowledge of child passenger safety" 


\section{Introduction}

Inappropriate restraint use, often an early transition to the next restraint type, by child occupants increases their risk of serious injury in crashes [1-3]. Recent research has focussed on children aged 4-8 years using adult seat belts instead of booster seats, which is associated with an increased injury risk [4]. In younger children, premature graduation to booster seats may also increase injury risk [5]. Early graduation from rear-facing to forward-facing restraints exposes infants to neck injury [6]. Demographic factors, parental attitudes and "negotiability" of restraint use, as well as parental knowledge of child occupant safety, have been reported to influence booster seat use among children aged 4-8 years [7-10]. However, few studies have examined the factors involved in restraint use across a broader range of child occupants. One study of child occupants (0-9 years) in fatal crashes [11] implicated driver restraint non-use, alcohol use, number of vehicle occupants and rural location as factors in booster non-use, but was not able to assess parental knowledge of child restraint use. More recently, Winston et al [12] noted that demographic factors, including race, family income and parental education were related to inappropriate restraint use in children aged under 9 years, but did not assess parental knowledge. Understanding how knowledge of child restraint "best practice" and other related factors influences restraint transitions may help in targeting appropriate educational programs.

This study aimed to investigate the types of restraints used and the influence of parental knowledge of child restraint "best practice" on child restraint usage for a sample of 0-10 year old Australian children. The study controls for a range of factors including demographics, family size, and rural or urban residence. It thus fills the gaps between studies of "booster age" children where parental knowledge has been studied, by examining a wider age range of children, where the effects of parental knowledge have not been studied.

\section{Methods}

\section{Sampling Plan}

A randomized telephone survey was used. The basic unit of sampling was individual households with children in the target age range (0-10 years) possessing a passenger vehicle. Telephone numbers were randomly selected from an electronic phone directory in New South Wales (NSW), Australia. Regional quotas were used for metropolitan (62.5\%), regional centres $(25.0 \%)$ and nonmetropolitan regions $(12.5 \%)$. Data for up to two randomly selected children $\leq 10$ years was collected from each household. The survey was conducted by a telephone research company. The final sample consisted of 619 children from 403 households. Of households contacted, $45 \%$ had no 
children in the target age group or no car, 32\% refused, $3 \%$ spoke a language for which an interpreter was not available, $15 \%$ were eligible but the quota in which they belonged was already full, and the remaining 5\% were recruited. Sample demographics were consistent with population data, except that non-English speakers were under-represented ( $8 \%$ sample vs $14 \%$ population), despite the availability of interpreters. Further demographic information is available in the supplemental data file. Parents were the most common respondents (mother 68.2\%, father 28.1\%). For simplicity, the respondent is referred to as the "parent", but data from all respondents is included (grandparent $2.7 \%$, other $0.9 \%$ ).

\section{Survey Method}

A structured questionnaire was used to collect information on family and child demographics and restraint practices. It was also used to assess parental knowledge, characteristics and beliefs. The questions are shown with the results below. Weight and height were recorded (if known). The reliability of these data were cross-checked by asking about the child's height relative to their peers and their clothing size. Restraint type was identified using verbal descriptions (e.g. an infant restraint faces the back of the car, and has a built-in harness). Demographic information collected included educational level and age of the respondent, household income, location (rural, regional centre, urban), and language spoken in the home.

\section{Data Coding and Analysis}

Age and size were used to determine the appropriate restraint (Table 1). These definitions are based on restraint use guidelines in Australia. The main difference from recommendations in other countries is that children from 6 months are allowed to face forward rather than requiring rearfacing up to 12 months. Height and weight information were used as the primary criteria for appropriateness of restraint use. If these were unavailable or unreliable, age was used (approximately one third of cases). If more than one restraint was appropriate for the child's size and age, either was deemed appropriate. 


\begin{tabular}{|c|c|c|}
\hline Age & Height/weight & Appropriate Restraint \\
\hline $0-6$ months & $\begin{array}{l}\text { Height }<700 \mathrm{~mm} \text {, } \\
\text { weight }<9 \mathrm{~kg}\end{array}$ & Rear facing infant restraint \\
\hline $\begin{array}{l}6 \text { months - } \\
4 \text { years }\end{array}$ & Weight $\leq 18 \mathrm{~kg}$ & Forward facing child restraint with inbuilt harness \\
\hline 4-8 years & $\begin{array}{l}\text { Height less than } 145 \mathrm{~cm} \text {, } \\
\text { weight }>18 \mathrm{~kg}\end{array}$ & $\begin{array}{l}\text { Belt-positioning booster seat with lap-sash seatbelt or } \\
\text { add-on } 4 \text { point child harness. }\end{array}$ \\
\hline $8-10$ years & Height above $145 \mathrm{~cm}$ & Adult seatbelt \\
\hline
\end{tabular}

Table 1. Appropriate restraint definitions used in Australia

Descriptive analysis included assessment of restraint type used by age, appropriateness of restraints, and the responses to knowledge questions.

Logistic regression modelling was used to analyse the data (AM v0.6.3, American Institutes of Research), incorporating corrections for clustering within households and stratification by region. Weighting factors were applied to account for the use of households as the sampling unit and to match the population of NSW households with children aged 0-10 years using population statistics for NSW for 2005 (from www.abs.gov.au). Post-stratification weighting for age distribution among survey regions was also performed by calculating a weight for each age child in each survey region based on the population data. Standard weighting procedures outlined in [13] were used. Maximum likelihood estimators and parameter estimates were obtained. The outcome variable was appropriate restraint use (yes/no). Odds ratios and $95 \%$ confidence intervals were calculated.

Independent variables included: parental education beyond secondary school (yes/no); parent had gone unrestrained in the last six months (yes/no); more than 2 children in the family (yes/no); English spoken at home (yes/no); the child ever sits in the front seat (yes/no); and the knowledge items in Table 2.

\begin{tabular}{lll} 
Item & Question Wording & Coding \\
\hline Type of restraint used is & $\begin{array}{l}\text { The type of child restraint my } \\
\text { child uses is chosen by me }\end{array}$ & $\begin{array}{l}\text { Neutral to strongly agree="yes" } \\
\text { Disagree to strongly disagree="no" } \\
\text { negotiable with the child? not negotiable with the } \\
\text { child }\end{array}$ \\
Knows that boosters & When do you think is it safe & Appropriate responses on age, height
\end{tabular}


should be used by children

4 years or older?

Knows that children

should be at least 8 years

to use adult belt alone?

Knows that boosters are

safer than belts alone for

4-8 year olds?

Knows that child restraint

systems are safer than

boosters for 2-4 year olds? for children to begin using a

booster seat?

When do you think is it safe

for children to begin using an

adult seat belt?

An adult belt offers a child

the same level of protection

as a booster

A booster seat offers the same

level of protection as a

forward facing child restraint or weight="yes"

Appropriate responses on age, height

or weight="yes"

Agree to strongly agree="yes"

Neutral to strongly disagree="no"

Agree to strongly agree="yes"

Neutral to strongly disagree="no"

Table 2. Knowledge items. Child restraint system and booster seat knowledge questions included in the survey of parents aged 0-10 years

Logistic regression models were constructed using data from the whole sample (children aged 0-10 years) and also for 1-4 years and 5-8 years subgroups, approximating subgroups of children using forward-facing child restraints and booster seats respectively.

\section{Results}

\section{Restraint Use}

The types of restraints used by children and their appropriateness, by age, are shown in Figure 1.

\section{Knowledge}

One observation is that it appears that parents "don't know what they don't know" about how best to restrain their children in cars. We base this observation on the fact that three quarters $(77 \%)$ of parents felt they knew everything they needed to know to restrain their child safely (agree or strongly agree with question worded as "I know everything I need to know to ensure my child is properly restrained in a car"), $7 \%$ were neutral and the remaining 16\% felt they did not know all they needed to know. There was no significant association between this knowledge belief and whether or not their children were appropriately restrained. While the majority of parents knew that the rear seat was safer for children (95\%), knowledge of restraint transitions and the relative benefits of different restraint types was not so good (30-53\%, depending on restraint type). Figure 2 
summarizes parental knowledge data for the overall sample and for two subgroups of particular interest, parents of 1-4 year olds and parents of 5-8 year olds.

\section{Logistic Regression Modelling}

Logistic regression results are summarised in Table 3. Knowledge of appropriate restraint transition points was associated with an increased likelihood of appropriate restraint use. The particular piece of knowledge that was most strongly associated with appropriate restraint use varied with age and was related to the next "appropriate" transition for that particular child (see Table 3). e.g. among parents of 1-4 year olds, knowledge that booster seats should be used by children aged 4+ years was associated with nearly fourfold higher odds that the child was appropriately restrained. Similarly, among parents of 5-8 year olds, knowledge that children should not use adult belts alone until at least 8 years of age (or appropriate height/weight) was associated with more than fivefold higher odds that the child was appropriately restrained. Clearly, for 5-8 year olds who are already inappropriately using adult belts, this represents the "current" restraint rather than the "next transition". Results do not merely indicate that better overall child restraint knowledge is associated with appropriate restraint use, because items of knowledge not relevant to the age of the specific child studied were not associated with higher appropriate restraint use. Knowledge of the relative safety benefits of child safety seats over boosters and boosters over seat belts did not significantly influence appropriate restraint use. Note that for knowledge questions, all respondents who did not possess the relevant knowledge (irrespective of the reason) were coded as "no".

As shown in Table 3, parental factors significantly associated with inappropriate use were: less formal parental education, willingness to negotiate restraint type with children, and allowing at least occasional front seating position.

Larger family size, as measured by the presence of more than two children in the household, was also significantly associated with inappropriate restraint use. English spoken at home was not a significant factor overall, but was significantly associated with appropriate restraint among the 5-8 years age group. As neither urban vs rural location nor household income contributed significantly to the model, they were removed as variables from the final model.

Whole Sample

0-10 year olds 1-4 year olds 5-8 year olds

$(n=619)$ $(\mathrm{n}=256)$ $(n=233)$ 
Odds Odds Odds

\begin{tabular}{|c|c|c|c|c|c|c|}
\hline Parent characteristics/knowledge & ratio & $95 \% \mathrm{CI}$ & ratio & $95 \% \mathrm{CI}$ & ratio & $95 \% \mathrm{CI}$ \\
\hline English spoken at home? (92.4\%) & 1.66 & $0.93-2.95$ & 0.38 & $0.11-1.35$ & 7.59 & $1.02-56.6$ \\
\hline \multicolumn{7}{|l|}{ Parent has gone unrestrained in last 6} \\
\hline months? $(6 \%)$ & 0.61 & $0.27-1.42$ & 0.20 & $0.06-0.67$ & 0.35 & $0.04-3.07$ \\
\hline \multicolumn{7}{|l|}{ Parent has secondary or less } \\
\hline education? (37.9\%) & 0.54 & $0.36-0.81$ & 0.41 & $0.23-0.74$ & 0.66 & $0.28-1.52$ \\
\hline \multicolumn{7}{|l|}{ Knows that boosters are safer than } \\
\hline belts alone for $4-8$ year olds? (46.4\%) & 1.25 & $0.83-1.88$ & 2.20 & $1.13-4.29$ & 1.07 & $0.55-2.07$ \\
\hline \multicolumn{7}{|l|}{ Knows that CRS are safer than } \\
\hline boosters for 2-4 year olds? (52.5\%) & 1.05 & $0.7-1.57$ & 1.34 & $0.73-2.47$ & 2.00 & $0.89-4.5$ \\
\hline
\end{tabular}

Knows that children should be at least

8 years to use adult belt alone?

$(30.2 \%)$

Knows that boosters should be used

by children 4 years or older? (36.2\%)

Type of restraint used is negotiable

with the child? $(7.8 \%)$

More than 2 children in household?

$(30.9 \%)$

Is child ever allowed to sit in the front seat? $(34.7 \%)$

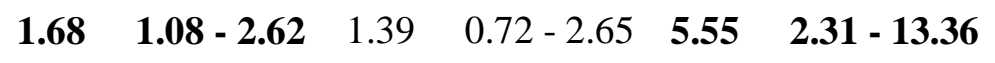

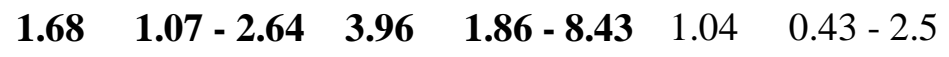

$\mathbf{0 . 4 7} \quad \mathbf{0 . 2 4}-\mathbf{0 . 9 3} \quad 1.18 \quad 0.21-6.66 \quad 0.35 \quad 0.08-1.6$

$\mathbf{0 . 5 6} \quad \mathbf{0 . 3 6}-\mathbf{0 . 8 6} \quad 0.81 \quad 0.44-1.51 \quad 0.67 \quad 0.28-1.61$

Table 3. Odds ratios for appropriate restraint use compared to inappropriate use. Bold figures show significant results. In each case, the referent category is the "no" response. Percentages after questions indicate the proportion of the sample with "yes" response.

\section{Discussion}

This study examines which specific components of parental restraint knowledge are associated with good restraint practices, and how these change for children of different ages and for users of different restraint types. The results demonstrate that parental knowledge of age-specific child restraint practices is a key factor predicting appropriate restraint use by children aged $\leq 10$ years, implying that educational campaigns may be more effective when parents are provided with information targeted to the age of their children. While this is unsurprising, it appeared that knowledge not relevant to the age of the child studied was not associated with appropriate restraint use. Precautionary behaviour relies on relevant knowledge (e.g. [14]). That is, to make appropriate 
restraint choices, parents must first know which restraints are appropriate for their child. That is, parents of 1-4 year olds need to know when to transition to a booster seat, and parents of 4-8 year olds need to know when to move from a booster to an adult seat belt. Increasing the overall knowledge of all parents may not be as effective. A recent phone survey evaluation of a booster seat campaign in Canada [15] suggested that parents retain specific information relevant to their child but not necessarily broader knowledge, and this study reinforces and extends that finding for a wider age range of children.

The majority of parents (76.5\%) in this study felt they knew all they needed to safely restrain their children. However, there was no association between parental confidence in their knowledge and either their actual knowledge or the appropriateness of their child's restraint. This implies that many parents "don't know what they don't know". Such overconfidence is a common cognitive error when underestimating risk or overestimating knowledge (for review see [16]). The overconfidence in knowledge seen here is concerning because self-efficacy is believed to be a key determinant of health-relevant behaviour (e.g. [14], [17]). Furthermore parental belief that they know all they need to know implies that they do not recognize that they have a problem. Thus they are at the precontemplation stage of the Stages of Change model [18], implying that they will not seek out or adopt appropriate behaviours, and that relevant messages may fall on deaf ears unless they are carefully targeted. Models that posit perceived risk as a determinant of health-relevant behaviour (e.g. [19] , [20]) also suggest that parents who think they are adequately protecting their children will be unmotivated to change their behaviour.

Having more than two children in the family, lower levels of parental education, allowing at least occasional front seat positioning, and parental/child restraint type negotiation were associated with less appropriate restraint use. These factors have previously been identified in studies of booster age children [7, 8, 12], but not in younger children using other restraints. A recent study [21] has suggested that the main barrier to booster seat use by children of less educated parents is lack of information about the consequences of non-use of booster seats. This is consistent with the findings of this study. In this study, negotiability of restraint use was most common for children aged 4-6 years. This coincides with children starting school, becoming more independent and negotiating on other issues. These broader developmental transitions may need to be taken into account when designing campaigns for this age group. The association between larger families and less appropriate restraint use is a novel finding. However others have noted that family size [22] and the number of booster aged children using boosters [9] influence the consistency of booster seat use. 
In the 1-4 years age group, parental restraint non-use was strongly associated with less appropriate restraint use by the child. Parental restraint practices have been associated with booster non-use previously [23] and that may reflect the influence of role models. However, in the younger children this may indicate how important parents think restraint use is, as they are primarily responsible for restraint choice and use in the youngest children. In the 5-8 years age group, a non-English speaking home was associated with inappropriate restraint use. This may indicate that educational campaigns targeted to non-English speaking families with children in this age group are required.

In surveys, there is the possibility that those who participate may differ systematically from those who do not. Unfortunately no information on non-respondents was collected. The telephone number pool was drawn from the electronic white pages for residential listings. It thus omits families without fixed telephone line services or unlisted numbers. Non-English speaking families were under-represented in the sample, despite attempts to mitigate this by using interpreters for common languages, and thus the results may not accurately reflect restraint practices in those families.

The self-report nature of this survey may raise concern about the potential for reporting bias and an underestimation of inappropriate restraint use. Two observations from the data limit the scale of such bias, however. The relatively poor parental knowledge suggests that many parents are not aware of the "right" thing to do, and inappropriate restraint use was commonly reported. While observational studies of restraint use by children in NSW have not been recently reported, the selfreported booster use rates found here are somewhat higher (15-20\%) than those seen in an observational study conducted in South Australia [24]. The current study presents self-reported "most commonly used restraint". Other studies (e.g. [8]), indicate that inappropriate restraint use is more common on short trips, such as those where the South Australian study collected data (travel to day-care centres and schools). Nonetheless, this data is likely to include some level of self-report "social desirability bias", for example reporting of booster use when parents know their children should use boosters, but don't routinely do so, and thus validation of the reported practices through observational studies is desirable.

\section{Implications for Prevention}

This study enhances understanding of child occupant safety by looking broadly at all restraint types and transitions, rather than focussing on just booster seats, as much of the recent literature has done [7-10]. It also examines which specific components of parental restraint knowledge are associated with good restraint practices, and how these change for children of different ages and for users of different restraint types. 
Novel findings from this study include that: (i) the restraint knowledge most strongly associated with appropriate restraint use is age-specific, and (ii) older children from non-English speaking and those from larger families are less likely to be appropriately restrained. This study also found that many parents mistakenly perceive that they know all they need to know to restrain their children safely. These findings have important implications for the design of effective educational campaigns to improve appropriate use of all child restraints, not just booster seats.

\section{Key Points}

- Parents appear to be overconfident in their knowledge of appropriate restraint usage for their children

- Inappropriate motor vehicle restraint use is widespread among children aged 2-8 years

- Parental knowledge of appropriate transition ages for the specific age of their child is associated with increased odds of appropriate restraint use

- Increased odds of inappropriate restraint use is also associated with lower parental education, larger families, and in booster-age children, with non-English speaking backgrounds

\section{Acknowledgements}

This research was supported by an Australian Research Council Linkage Grant, with partner funding from the Motor Accidents Authority of NSW and the Roads and Traffic Authority of NSW. LEB and CFF are supported by NHMRC research fellowships. JH is supported by an NHMRC Population Health Capacity Building Grant in Injury Prevention, Trauma and Rehabilitation (ITR).

\section{References}

1 Brown J, McCaskill ME, Henderson M, et al. Serious injury is associated with suboptimal restraint use in child motor vehicle occupants. Journal of Paediatrics and Child Health 2006;42:345-349.

2 Nance ML, Lutz N, Arbogast KB, et al. Optimal restraint reduces the risk of abdominal injury in children involved in motor vehicle crashes. Ann Surg 2004;239:127-131.

3 Winston FK, Durbin DR, Kallan MJ, et al. The danger of premature graduation to seat belts for young children. Pediatrics 2000;105:1179-1183.

4 Durbin DR, Elliott MR, Winston FK. Belt-positioning booster seats and reduction in risk of injury among children in vehicle crashes. Jama 2003;289:2835-2840.

5 Trosseille X, Chamouard F, Tarriere C. Abdominal injury risk to children and its prevention. In: Proceedings of International IRCOBI Conference on the Biomechanics of Impact; 1993. p. 153-163 6 Howard AW. Automobile restraints for children: a review for clinicians. Canadian Medical Association Journal 2002;167:769-773. 
7 Rivara FP, Bennett E, Crispin B, et al. Booster seats for child passengers: lessons for increasing their use. Inj Prev 2001;7:210-213.

8 Simpson EM, Moll EK, Kassam-Adams N, et al. Barriers to booster seat use and strategies to increase their use. Pediatrics 2002;110:729-736.

9 Bingham CR, Eby DW, Hockanson HM, et al. Factors influencing the use of booster seats: A state-wide survey of parents. Accid Anal Prev 2006;38:1028-1037.

10 Ebel BE, Koepsell TD, Bennett EE, et al. Too small for a seatbelt: predictors of booster seat use by child passengers. Pediatrics 2003;111:e323-327.

11 Agran PF, Anderson CL, Winn DG. Factors associated with restraint use of children in fatal crashes. Pediatrics 1998;102:e39-.

12 Winston FK, Chen IG, Smith R, et al. Parent driver characteristics associated with sub-optimal restraint of child passengers. Traffic Injury Prevention 2006;7:373-380.

13 Lohr S. Sampling : design and analysis. Pacific Grove: Duxbury Press; 1999.

14 Caltabiano ML, Sarafino EP. Health Psychology: Biopsychosocial Interactions, An Australian Perspective. Milton, Queensland: John Wiley \& Sons Australia; 2002.

15 Howard A, Beben N, Rothman L, et al. Evaluation of Safe Kids Week 2004: Age 4 to 9? It's Booster Seat Time! Inj Prev 2006;12:316-319.

16 Dunning D, Heath C, Suls JM. Flawed self-assessment implications for health, education, and the workplace. Psychological Science in the Public Interest, Supplement 2004;5:69-106.

17 Taylor SE. Health Psychology. 5th ed. New York, NY: McGraw Hill; 2003.

18 Prochaska JO, DiClemente CC, Norcross JC. In search of how people change: Applications to addictive behaviors. American Psychologist 1992;47:1102-1114.

19 Ajzen I, Madden TJ. Prediction of goal-directed behavior: Attitudes, intentions, and perceived behavioral control. Journal of Experimental Social Psychology 1986;22:453-474.

20 Becker MH, Rosenstock IM. Compliance with medical advice. In: Steptoe A, Mathews A, editors. Health Care and Human Behaviour. London: Academic Press; 1984.

21 Winston FK, Erkoboni D, Xie D. Identifying interventions that promote belt-positioning booster seat use for parents with low educational attainment. J Trauma 2007;63:S29-38.

22 Durbin DR CR, Chen I, Williams A, Wells J. Variation in child restraint transitions and consistency of restraint use. In: Proceedings of Annual Association for the Advancement of Automotive Medicine Conference; 2003. p. 622-624.

23 Eby DW, Bingham CR, Vivoda JM, et al. Use of booster seats by Michigan children 4-8 years of age. Accid Anal Prev 2005;37:1153. 


\section{Figure Legends:}

Figure 1. Reported restraints used by age of child, according to (a) Restraint type (b)

Appropriateness of restraint. Note that "harness" refers to an add-on 4 point child harness that can be used with the adult seatbelt and attaches to the child restraint tether point in the vehicle.

Figure 2. Parental knowledge of restraint safety and transitions. Definitions are given in the text. $\mathrm{CRS}=$ forward facing child restraint system. 

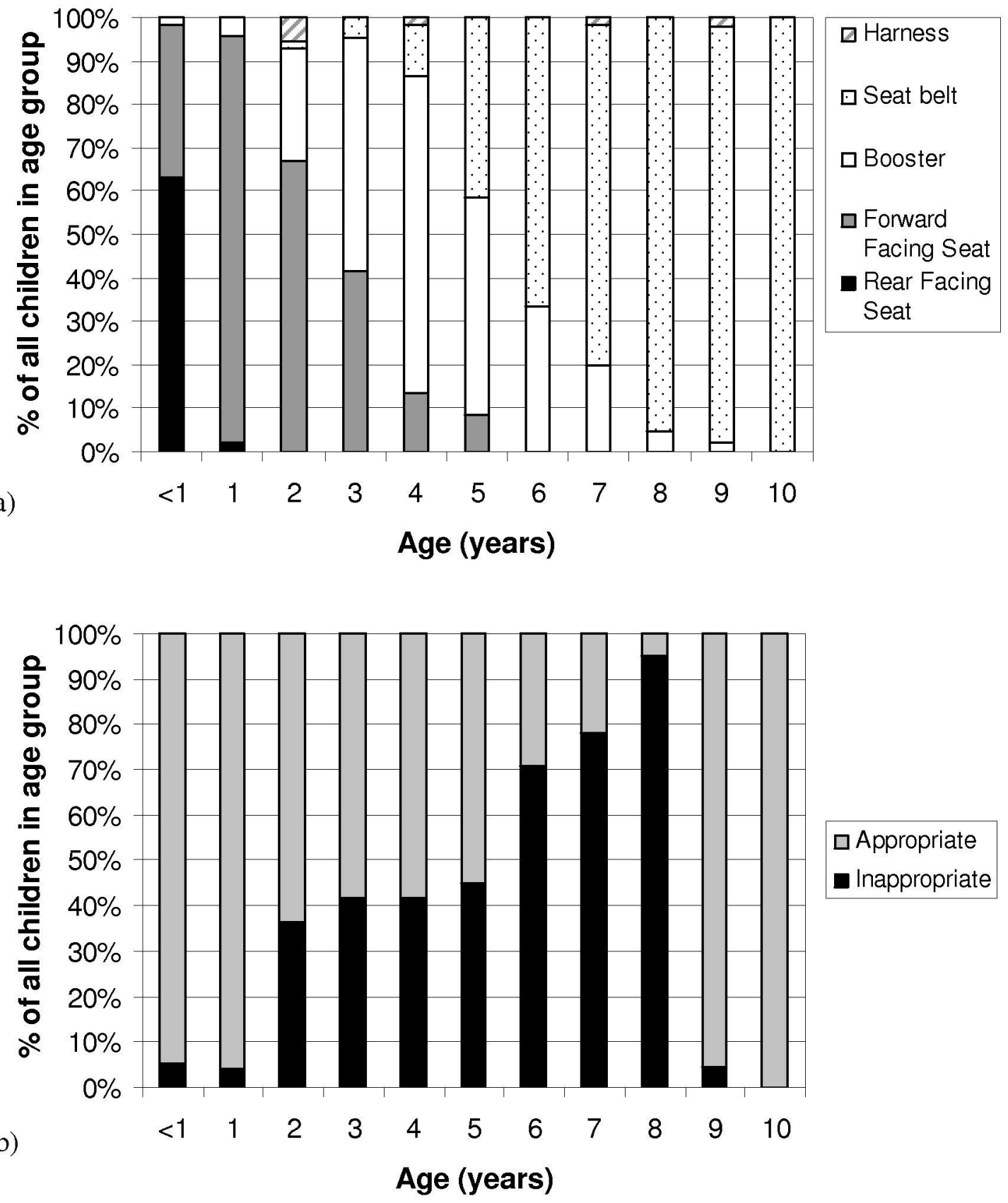

Figure 1. Reported restraints used by age of child, according to (a) Restraint type (b) Appropriateness of restraint 


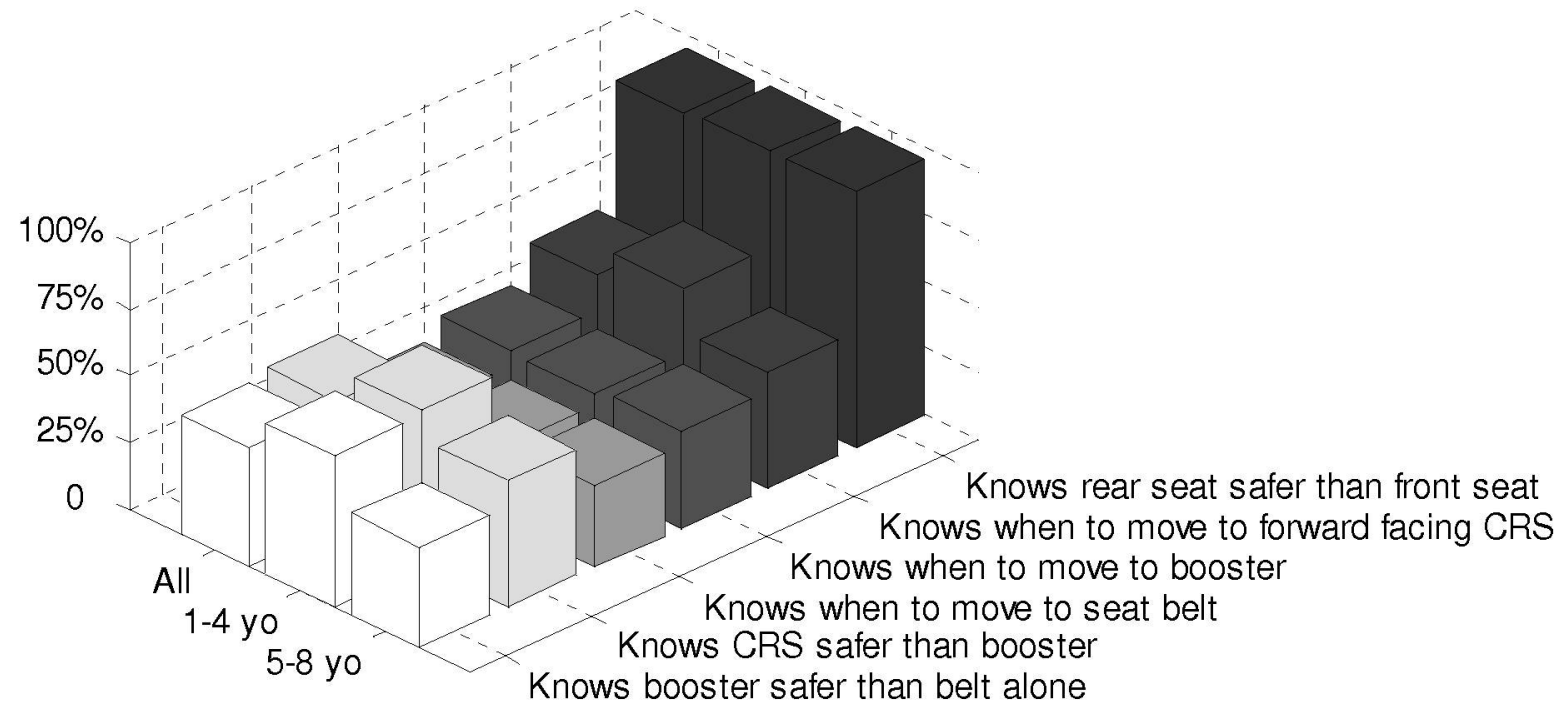

Figure 2. Parental knowledge of restraint safety and transitions. Bars indicate proportion of respondents in the whole sample (AII) and respondents with children in each of the noted age groups (1-4 year olds, 5-8 year olds) who possessed the indicated knowledge. Note that a parent with children in both 1-4 and 5-8 age groups will be included in both subgroups. Definitions are given in the text. CRS = forward facing child restraint system. 